Красинский Владислав Вячеславович

кандидат юридических наук, эксперт

Российского общественного института

избирательного права (РОИИП)

\title{
ПРЕСТУПНЫЕ ОРГАНИЗАЦИИ (СООБЩЕСТВА) КАК ЭЛЕМЕНТ ПОЛИТИЧЕСКОЙ СИСТЕМЫ РОССИЙСКОГО ОБЩЕСТВА
}

Красинский B.B. Преступные организации (сообщества) как элемент политической системы российского общества // Человеческий капитал. 2011. № 1. С. 95-99; www.krasinskiy.ru

Аннотация: В статье анализируются актуальные проблемы криминализации российской политической системы. Автор изучает участие преступных организаций (сообществ) в политико-правовых процессах и показывает место и роль криминальных структур в политической системе общества.

Ключевые слова: политическая система, защита конституционного строя, преступные организации (сообщества), криминальные структуры в политической системе.

The article examines actual problems of criminalization of the Russian political system. The author studies participation of the criminal organizations (communities) in politiko-legal processes and show a place and a role of criminal structures in political system of a society.

Key words: political system, the criminal organizations (community), protection of constitutional order, criminal structures in political system.

25 февраля 2009 г., выступая на расширенном заседании Коллегии Генеральной прокуратуры Российской Федерации, Президент Российской Федерации Д.А. Медведев отметил, что на муниципальном уровне наблюдается довольно высокое представительство криминалитета. «Криминальные элементы, авторитеты и авторитетики местного масштаба не должны находиться в местных органах власти, а их там достаточное количество», - заявил глава государства ${ }^{1}$.

Криминализация российской политической системы осуществляется в двух основных направлениях: путем участия представителей организованной преступности в выборах с последующим избранием в органы власти и путем назначения представителей криминалитета на ключевые должности коррумпированными чиновниками государственного и муниципального аппаратов.

16 ноября 2010 г. на заседании Координационного совета по защите избирательных прав граждан, проходившего в Общественной палате Российской Федерации, Председатель ЦИК России Чуров В.Е. сообщил, что 
в ходе выборов разного уровня заметно возросло число судимых кандидатов, баллотирующихся на выборные должности. Особенно это характерно для муниципальных выборов. Так, на выборах в Единый день голосования 10 октября 2010 г. представители криминалитета выдвигались в Московской области, Мурманской области (Кандалакша, Апатиты) и ряде других регионов (Республика Дагестан, Ростовская, Новгородская, Самарская области). Чуров В.Е. отметил, что при организации данных выборов были выявлены три кандидата с неснятыми судимостями за совершение особо тяжких преступлений.

В выборах 13 марта 2011 г. также участвовало значительное количество лиц с криминальным прошлым. В одной только Владимирской области в депутаты и на выборные должности баллотировалось 170 кандидатов, имеющих судимость. После информирования региональных отделений политических партий таких кандидатов стало 120. В связи с наличием неснятых (непогашенных) судимостей за тяжкие и особо тяжкие преступления из списков были исключены 4 кандидата.

В ходе выборов 13 марта 2011 г. кандидатом в Калининградскую областную Думу был выдвинут депутат Полесского городского поселения Зубриков В. («Зубрик», «Витек»), известный УВД по Калининградской области как организатор и активный участник «Полесской организованной преступной группы».

Криминализация российского общества справедливо рассматривается ведущими российскими юристами в качестве угрозы конституционному строю. По словам Председателя Конституционного Суда Российской Федерации В. Зорькина, «с каждым днем становится все очевиднее, что сращивание власти и криминала по модели, которую сейчас называют «кущевской», - не уникально. Что то же самое (или нечто сходное) происходило и в других местах - в Новосибирске, Энгельсе, ГусьХрустальном, Березовске и так далее... Криминал подрывает основы нашей хрупкой правовой системы, основы нашей социальной, политической и экономической жизни. Он посягает на все социальные скрепы. Он разлагает ткань нашего весьма незрелого гражданского общества. А порою и выступает 
в качестве соискателя на роль социального начала, подменяющего собой гражданское общество. Криминал подрывает основы общественного благополучия и стабильности. И, конечно же, он превращается в основное препятствие на пути общественного развития» ${ }^{1}$.

Рост активности организованных преступных организаций (сообществ), связанный с попытками избрания в органы государственной власти и органы местного самоуправления, обусловлен заинтересованностью преступных организаций в постоянном наращивании своих доходов, прямой зависимостью официальной и теневой экономической деятельности от политической конъюнктуры в Российской Федерации, желанием руководителей и участников криминальных структур обеспечить личную безопасность ${ }^{2}$.

Социальной базой обновленных преступных организаций становится поколение конца 80-х годов XX века, мировоззрение которого формировалось на уголовной субкультуре, антиобщественных нормах и героизации представителей криминалитета в средствах массовой информации. В связи с расширением полномочий органов местного самоуправления по вопросам земельных отношений (проведение землеустроительных работ, переоформление прав на землю, утверждение правил землепользования и застройки, распоряжение земельными участками) наиболее привлекательным сегментом трудоустройства кандидатов, представляющих интересы криминалитета, являются выборные муниципальные должности и представительные органы местного самоуправления.

Для проникновения в органы власти криминальными элементами используется смена фамилий, удаление своих персональных данных из региональных баз правоохранительных органов, а также продвижение «незасвеченных» ставленников (нередко близких родственников), не

1 Зорькин В. Конституция против криминала // Рос. газ. 2010. 10 декабря.

2 Красинский B.B. Правовое обеспечение защиты конституционного строя России в избирательном процессе: Монография. М.: Новый индекс, 2010. С. 42; Красинский В.В. Юридическое обеспечение выборов в интересах защиты конституционного строя и национальной безопасности. М.: Новый индекс, 2010. С. 47-52. 
имеющих судимостей и выявленных связей с организованной преступностью. В ряде субъектов Российской Федерации материалы оперативно-справочных учетов информационных центров МВД, ГУВД, УВД субъектов Российской Федерации сознательно искажаются коррумпированными сотрудниками правоохранительных органов, в полиции и судебной системе проходят службу амнистированные участники незаконных вооруженных формирований и лица, в отношении которых уголовное преследование было прекращено за истечением срока давности и примирением сторон ${ }^{1}$.

Анализ материалов избирательных кампаний свидетельствует, что все политические партии (и их региональные отделения) включали и продолжают включать в свои списки кандидатов из числа представителей криминалитета.

Потенциал организованных преступных групп активно используется на всех стадиях избирательного процесса.

На этапе выдвижения преступные организации на возмездной основе включают своих кандидатов в списки избирательных объединений и осуществляют угрозы в адрес кандидатов - конкурентов. В нападениях на активистов партий принимают участие ранее судимые за тяжкие преступления граждане. В ходе предвыборной агитации криминальные агитаторы осуществляют подкуп избирателей, распространяют подложные и анонимные агитационные материалы, допускают иные нарушения законодательства о выборах.

15 сентября 2010 г. ОМОН Республики Тыва «сорвал» встречу избирателей с представителями регионального отделения политической партии «Справедливая Россия» в буддийском монастыре Устуу-Хурээ. 6 кандидатов в Верховный Хурал Тувы приехали по приглашению настоятеля для проведения обряда благоденствия, призванного обеспечить победу партии на выборах. После обряда была запланирована встреча с избирателями.

\footnotetext{
${ }^{1}$ Примером могут служить Республика Дагестан и Чеченская Республика.
} 
В 15.30 в дежурную часть ОВД по Дзун-Хемчикскому району поступил звонок от неизвестного о том, что на территории храма Устуу-Хурээ проводится сбор лиц, ранее привлекавшихся к уголовной ответственности. По итогам проверки в райотдел были доставлены 42 человека для установления личности. В отношении 5 из них составлен протокол об административном правонарушении по статье 20.1 КОАП за оказание сопротивления при задержании. У одного из граждан изъято вещество с характерным запахом дикорастущей конопли. После разбирательства все задержанные были отпущены. Откуда в храме оказалось 42 ранее судимых человека, в МВД Республики Тыва пояснить не смогли ${ }^{1}$.

Криминальные структуры осуществляют скрытое и легальное финансирование избирательных кампаний отдельных кандидатов и избирательных объединений, в результате чего выборы превращаются в процедуру «купли-продажи» власти.

Примером может служить уголовное дело в отношении депутата Государственной Думы Федерального Собрания Российской Федерации В.И. Головлева. В.И. Головлев, будучи заместителем главы администрации Челябинской области, незаконно провел приватизацию ряда государственных предприятий области в интересах конкретных хозяйствующих субъектов, за что в последующем, после выдвижения его кандидатом в депутаты Государственной Думы Федерального Собрания Российской Федерации руководителями этих хозяйствующих субъектов были перечислены денежные средства в размере 97 миллионов рублей в его избирательный фонд². Другим примером коррупции в избирательном процессе является уголовное дело в отношении 14 депутатов Тверской городской Думы во главе с ее бывшим председателем В. Почтаревым. Указанная группа «народных представителей» отрабатывала деньги

${ }^{1}$ Выборы в России 10 октября 2010 года. Аналитический доклад. М.: Голос, 2010. С. 102.

2 Цит. по Кабанов П.А., Райков Г.И., Чирков Д.К. Политическая коррупция в условиях реформирования российской государственности на рубеже веков: Монография. М.: Дружба народов, 2008. С. 63. Данное уголовное дело было прекращено в связи с убийством В.И. Головлева неустановленными лицами. 
финансовых спонсоров их избирательной кампании путем принятия противоправных нормативных актов ${ }^{1}$.

Тема связи с криминалом может использоваться для дискредитации кандидатов-соперников или отказов в регистрации кандидатов. Например, в ходе выборов 13 марта 2011 г. кандидату в депутаты Совета народных депутатов г. Владимира двадцать шестого созыва по одномандатному избирательному округу № 10 г. Мартынову В.Н. (якобы «в криминальных кругах - Мартын»), были приписаны 6 статей УК РФ, хотя на сайте избирательной комиссии в сведения о наличии у кандидата неснятых и непогашенных судимостей не подтвердились.

В ходе избирательной кампании, назначенной на 10 октября 2010 г., в Самарской области было отказано в регистрации кандидату А. Деминой, на протяжении четырех созывов являвшейся депутатом Самарской губернской Думы, на основании того, что в подписных листах не были указаны сведения об отсутствии у нее судимости ${ }^{2}$. В соответствии с пунктом 9 статьи 37 Федерального закона «Об основных гарантиях избирательных прав и права на участие в референдуме граждан Российской Федерации» сведения о судимости подлежат указанию в подписном листе исключительно в случае ее наличия у кандидата. Сведения об отсутствии судимости не подлежат указанию, поэтому отказ в регистрации на таком основании нельзя признать законным.

Приведенные примеры свидетельствуют об актуальности проблемы криминализации политической системы российского общества и необходимости адекватного противодействия попыткам проникновения преступных организаций (сообществ) в органы государственной власти и местного самоуправления.

Как отмечают отечественные исследователи, «непосредственное воздействие преступных сообществ на политико-правовые процессы в

${ }^{1}$ Андриянов О., Иванова Т. Тверская застава // Рос. газ. 2007. 25 августа; Никитина M. Коррупционная дюжина // Рос. газ. 2007. 7 декабря.

${ }^{2}$ Аналитический обзор по результатам мониторинга региональных и муниципальных выборов 10 октября 2010 г. М.: Ассоциация некоммерческих организаций по защите избирательных прав «Гражданский контроль». С. 2. 
российском обществе свидетельствует в пользу их признания в качестве самостоятельного компонента политической системы Российской Федерации» ${ }^{1}$.

По мнению В.М. Сырых, «в настоящее время организованная преступность в Российской Федерации является общеизвестным и бесспорно установленным фактом, с которым должны считаться как государство, так и юридическая наука. В соответствие с реалиями современной жизни надлежит привести и теоретические представления о политической системе Российской Федерации, дополнив ее таким специфическим, но действенным компонентом, как преступные сообщества»².

Другой позиции придерживается О.В. Мартышин: «Элементами политической системы являются именно легальные, не запрещенные законом организации, деятельность которых не направлена на разрушение господствующей системы. ... Нельзя считать элементом политической системы организации, стремящиеся свергнуть существующий строй, разрушить господствующую политическую систему и установить новую» ${ }^{3}$.

Аргументация О.В Мартышина представляется дискуссионной, поскольку подавляющее большинство преступных организаций (сообществ) не преследует экстремистских целей - насильственного свержения конституционного строя и разрушения господствующей политической системы. Криминальные структуры, напротив, стремятся использовать существующий государственный механизм и муниципальный аппарат в своих интересах, максимально оперативно и органично легализовать свой статус в политической системе.

Чтобы отделить преступные организации (сообщества) от иных социальных явлений и институтов политической системы, проведем терминологический анализ рассматриваемой предметной области.

${ }^{1}$ Cырых B.M. Теория государства и права: Учебник. - М.: Юридический Дом «Юстицинформ», 2001. С.430.

\footnotetext{
${ }^{2}$ Теория государства и права: Учебник / Под ред. В.К. Бабаева. М.: Юрист, 2007. С. 140.

${ }^{3}$ Теория государства и права: Учебник / Под ред. О.В. Мартышина. М.: Норма, 2007. C. 183 .
} 
В соответствии с частью 4 статьи 35 УК РФ преступное сообщество (преступная организация) может осуществлять свою преступную деятельность либо в форме структурированной организованной группы, либо в форме объединения организованных групп, действующих под единым руководством.

Под структурированной организованной группой следует понимать группу лиц, заранее объединившихся для совершения одного или нескольких тяжких либо особо тяжких преступлений, состоящую из подразделений (подгрупп, звеньев и т.п.), характеризующихся стабильностью состава и согласованностью своих действий. Структурированной организованной группе, кроме единого руководства, присущи взаимодействие различных ее подразделений в целях реализации общих преступных намерений, распределение между ними функций, наличие возможной специализации в выполнении конкретных действий при совершении преступления и другие формы обеспечения деятельности преступного сообщества (преступной организации $)^{1}$.

Объединение организованных групп предполагает наличие единого руководства и устойчивых связей между самостоятельно действующими организованными группами, совместное планирование и участие в совершении одного или нескольких тяжких или особо тяжких преступлений, совместное выполнение иных действий, связанных с функционированием такого объединения ${ }^{2}$.

Руководство преступным сообществом (организацией) может выражаться: в определении целей, в разработке общих планов деятельности преступного сообщества (преступной организации), в подготовке к совершению конкретных тяжких или особо тяжких преступлений, в распределении ролей между членами сообщества, в организации материально-технического обеспечения, в разработке способов совершения и

${ }^{1}$ Пункт 3 Постановления Пленума Верховного Суда Российской Федерации от 10 июня 2010 г. № 2 «О судебной практике рассмотрения уголовных дел об организации преступного сообщества (преступной организации) или участии в нем (ней)» // Рос. газ. 2010. 17 июня.

2 Там же. Пункт 5 
сокрытия совершенных преступлений, в принятии мер безопасности в отношении членов преступного сообщества, в конспирации и в распределении средств, полученных от преступной деятельности. К функциям руководителя преступного сообщества (преступной организации) следует также относить принятие решений и дачу соответствующих указаний участникам преступного сообщества (преступной организации) по вопросам, связанным с распределением доходов, полученных от преступной деятельности, с легализацией (отмыванием) денежных средств, добытых преступным путем, с вербовкой новых участников, с внедрением членов преступного сообщества (преступной организации) в государственные, в том числе правоохранительные, органы ${ }^{1}$.

По мнению В.М. Сырых, от легально действующих общественных объединений преступное сообщество отличается двумя признаками ${ }^{2}$ :

1) оно действует нелегально (организация и деятельность прямо запрещены законом);

2) сообщество ставит своей целью совершение тяжких или особо тяжких преступлений типа захвата власти неконституционным путем, пропаганды национальной или религиозной розни, совершения хищений имущества в больших размерах, совершения заказных убийств и др.

В зависимости от сферы противоправных посягательств преступные сообщества подразделяются В.М. Сырых на уголовные и политические

Интересы уголовных преступных сообществ остаются преимущественно в экономической сфере. Такие сообщества, как правило, не поднимаются до уровня политической деятельности и не ставят своей непосредственной целью воспрепятствование деятельности государства, его органов, смену власти или политического режима. Политические преступные сообщества, наоборот, ставят своей непосредственной целью захват власти неконституционным вооруженным путем, организацию мятежей, а также

\footnotetext{
${ }^{1}$ Там же. Пункт 10

${ }^{2}$ Теория государства и права: Учебник / Под ред. В.К. Бабаева. М.: Юрист, 2007. С.

${ }^{3}$ Там же. С. 142.
} 141. 
совершение действий, препятствующих нормальной деятельности государства, его органов и должностных лиц.

Такая классификация преступных сообществ нуждается в корректировке. В настоящее время практически не осталось «чистых» уголовных или политических преступных сообществ. Любое преступное сообщество заинтересовано в стабильном финансировании, прочной экономической базе и надежном политическом прикрытии. Поэтому в деятельности подавляющего большинства преступных организаций (сообществ) проявляется политический аспект в виде стремления к завоеванию (удержанию, использованию) государственной власти, связанного с последующей переориентацией государственных и муниципальных политических институтов на постоянное обслуживание криминальных интересов.

Анализ места и роли преступных организаций (сообществ) в политической системе общества следует проводить с учетом требований (критериев), предъявляемых ко всем институтам политической системы.

В соответствии с положениями теории государства институты политической системы общества должны отвечать двум основным критериям: организационному и политическому를.

Организационный критерий означает внутреннюю упорядоченность и оформленность элемента (наличие специфических задач, функций, иерархия, автономность), а политический критерий предполагает политический характер деятельности элемента, которая раскрывается в нескольких аспектах:

a) способность выражать политические интересы определенной социальной группы;

${ }^{1}$ Существуют различные точки зрения в отношении количества критериев отбора элементов институциональной подсистемы политической системы (политической организации) общества. Так, Ф.М. Бурлацкий и В.Е. Чиркин предлагают семь таких критериев, В.Н. Жуков, С.А. Комаров и М.Н. Марченко - три. Несмотря на многообразие мнений, все авторы признают наличие организационного и политического критериев. 
б) способность участвовать в политической жизни, т.е. иметь непосредственное или опосредованное отношение к завоеванию, удержанию или использованию государственной власти;

в) способность следовать в своей деятельности определенной политической программе и руководствоваться политическими нормами.

Современные преступные организации (сообщества), действующие на территории Российской Федерации, соответствуют названным критериям.

К числу специфических задач преступных организаций (сообществ) по участию в политической системе следует отнести:

- замещение выборных должностей муниципальных образований с целью последующего использования должностных полномочий в интересах преступных организаций (сообществ);

- формирование в федеральных и региональных органах государственной власти депутатского корпуса, лоббирующего принятие нормативных правовых актов, политических, административных и иных официальных решений в интересах преступных организаций (сообществ);

- приобретение иммунитетов выборных должностных лиц и депутатской неприкосновенности.

Названные политические задачи преступных организаций (сообществ), участвующих в политической системе, неразрывно связаны с экономическими:

- легальный передел рынков сырья, недвижимости, товаров и услуг в интересах организованных преступных групп;

- установление контроля над прибыльными бюджетообразующими предприятиями и высокорентабельными отраслями экономики (строительство, топливно-энергетический комплекс, добывающая промышленность, учреждения кредитно-финансовой сферы);

- неправомерное получение дополнительных льгот и преференций (экспортно-импортные операции, налоги, лицензионная деятельность, квотирование)

- неправомерное получение кредитов и управление бюджетными средствами в интересах преступных организаций (сообществ). 
Масштаб задач, стоящих перед преступными организациями (сообществами), определяет выбор представителями криминалитета соответствующих методов борьбы за государственную и муниципальную власть.

Роль преступных организаций (сообществ) в политической системе общества выражается в их функциях, к числу которых относятся:

a) представительство социально-политических интересов определенной части общества;

б) фактическое осуществление отдельных государственно-властных полномочий («теневая» юстиция, воспитание и трудоустройство подростков из неблагополучных семей и др.);

в) разработка и реализация политической стратегии и тактики борьбы за государственную власть в ходе выборов.

Функция представительства социально-политических интересов проявляется в том, что кандидаты преступных организаций (сообществ) выражают интересы ряда социальных групп и располагают определенной поддержкой в обществе. По данным проведенного Фондом «Общественное мнение» Всероссийского опроса городского и сельского населения 44 субъектов Российской Федерации, 4 \% опрошенных граждан полагают, что навести порядок в государстве могут только представители организованных преступных групп, потому что «криминал привык к дисциплине», «порядка больше в их среде». $2 \%$ респондентов считают представителей уголовной среды честными, справедливыми, умными людьми с большим жизненным опытом, умеющими держать данное слово («они жизнь лучше понимают», «они зачастую более порядочные, чем политики») ${ }^{1}$.

В общественном сознании населения некоторых субъектов Российской Федерации сформировались толерантность и симпатии среди населения в отношении избранных в органы государственной власти и местного самоуправления представителей преступных организаций и связанных с уголовной средой кандидатов на выборные должности. В ряде субъектов

1 Петрова А. Криминал во власти - обычное явление? //bd.fom.ru/report/map/projects. См. также. Труд. 2004. 10 августа. № 148. 
Российской Федерации представители криминалитета пользуются уважением среди населения. Необходимо отметить, что представители организованных преступных групп активно поддерживают усиление криминального влияния в обществе, в том числе в молодежной среде. Известны случаи организации спортивных секций, клубов по интересам, развлекательных центров и дискотек, находящихся под влиянием представителей организованной преступности и финансирующихся из их источников.

Фактическое осуществление преступными организациями (сообществами) отдельных государственно-властных полномочий, обращение населения за помощью к криминалитету обусловлено наличием у криминальных структур выстроенной системы управления, в которой сочетаются постановка четких и реальных задач, минимизация бюрократической волокиты, распределение ролей, строгая подчиненность, контроль и взаимная ответственность исполнителей, а также аппарата принуждения.

Как уже отмечалось выше, преступные организации (сообщества) принимают активное участие в борьбе за государственную власть ${ }^{1}$. Экономическая состоятельность преступных организаций (сообществ) и подконтрольных им финансово-промышленных структур позволяет представителям криминалитета выступать основными спонсорами избирательных кампаний, контролировать деятельность судей, избирательных комиссий, правоохранительных органов и СМИ. В период подготовки и проведения выборов кандидаты, представляющие интересы преступных сообществ, выступают как активные сторонники реализации партийных программ, демонстрируют готовность и умение решать социально-значимые вопросы: асфальтируют дороги, устанавливают памятные доски воинам-участникам Великой Отечественной Войны, строят детские площадки, стремятся участвовать в осуществлении культурновоспитательных и патриотических мероприятий.

1 Подробней см. Красинский В.В. Проблемы борьбы с криминалитетом в ходе избирательных кампаний // Юридический мир. 2003. № 9. С. 4-8; Красинский В.В. Участие организованных преступных групп в избирательных кампаниях // Политика и общество. 2008. № 4. С. 7-13. 
Проведенный анализ места и роли преступных организаций (сообществ) в политической системе российского общества свидетельствует об институционализации и частичной легализации криминальных структур в политической системе и исключительной общественной опасности подобного явления.

Противодействие дальнейшему проникновению преступных организаций (сообществ) в органы власти и их сращиванию с другими институтами политической системы российского общества требует незамедлительной и планомерной работы в рамках следующих основных направлений:

тесная координация деятельности правоохранительных органов, СМИ, политических партий и общественных организаций по недопущению партийной коррупции и избрания (назначения) представителей криминалитета в органы государственной власти и местного самоуправления;

совершенствование законодательства о выборах, государственной и муниципальной службе путем установления правовых ограничений на избрание (назначение на должности) в органы государственной власти и местного самоуправления лиц, находящихся под следствием, в розыске, имеющих судимость за совершение тяжких или особо тяжких преступлений;

усиление требований к замещению должностей правоохранительной службы;

введение обязательных антикриминальных проверок всех кандидатов, поступающих на гражданскую, военную и правоохранительную службу;

ликвидация (ограничение числа и содержания) иммунитетов выборных должностных лиц и депутатской неприкосновенности.

Красинский Владислав Вячеславович кандидат юридических наук, член

Общественного научно-методического

Совета при ЦИК России

Krasinskiy Vladislav V., P.H.D., the member of public scientifically-methodical 
Council at the Central Electoral Commission of Russian Federation 